\title{
Exploring the contribution of Neuroarchitecture in learning environments design "A review"
}

\author{
Dina Ezzat Ahmed, Prof. Dr. Shaimaa Kamel, \\ Prof. Dr. Laila Khodeir
}

\section{Ain Shams University Faculty of Engineering Department of Architecture}

\begin{abstract}
:
Basically, the built environment must insure the physical and mental health of its users, since it's where we spend approximately $80-90 \%$ of our lives, according to the World Health Organization (WHO), which gives a focal dimension for the opportunities to study the effect of the architectural surroundings on users brains.

Neuroarchitecture is the field where architects collaborate with neuroscientists to explore scientifically the relationship between individuals and their surrounding environment. Despite the recent presence of multiple studies focusing on the neuroscience driven architecture, detailed research applying it on specific building types, as learning environments is very limited.

This paper aimed to explore the interrelationship between the field of neuroscience and architecture, and to investigate the constructive contribution of neuroscience in the design of educational facilities; targeting to explain the correlation between the neuroscientific data and the existing architectural interpretations. This research has been performed through qualitative research; starting with data collection, based on articles, papers, studies (library information), followed by descriptive, thematic, and narrative analysis methods; and then it has critically assessed experiments with the same vision of investing the neurological findings in creating educational spaces' design framework. Lastly, the paper concluded that the built environment widely contribute to the development of children's brains and their learning processes' quality; Further analysis also indicated the inevitable importance of children engagement in the design processes of their spaces.
\end{abstract}




\section{Keywords:}

Neuroarchitecture - Built environment - Brain development - Learning experience.

\section{Introduction:}

\section{Neuroscience Driven Architecture - Intro to Neuroarchitecture}

Neuroarchitecture is the interdisciplinary field that ensures the creation of environments able to optimize the human behavior, well-being, and performance. Correspondingly, according to Dunn (2012), the active immersion of children in sensor-rich environments guarantee the reinforcement of their brain development, and can foster the learning experience.

\subsection{Neuroarchitecture Beginning}

According to Samaržija (2018), the actual beginning of the field of neuroarchitecture was when the virologist who discovered the polio cure, attributed his success to "the intellectual restorative environment" of a monastery he retreated to. And later, it gained momentum in 2014 when two of the founders of the Academy of Neuroscience for architecture (ANFA) won a Nobel prize for their discovery of brain cells that are attuned to place.

\subsection{Neuroscientific Tools and Methodologies}

The recent technological development has empowered neuroscientists by the ability to measure accurately the brain activities and therefore its direct relationship with the environment. According to Maleki and Bayzedi (2018), the most recent efficient neuroscientific tools used to measure and understand brain activities are:

- FMRI: Functional Magnetic Resonance Imaging

- QEEG: Quantitative Electroencephalography

- Facial coding 
Samaržija in her paper "Epistemological implications of Neuroarchitecture" developed a preliminary neuroarchitecture research methodology, considered as a valuable contribution to this area of research. It consisted of five main steps as follows:

- Hypothesis about the influence of environmental settings on cognition.

- Defining research methodology

- Predicting psychological reactions

- Testing conclusions on real examinants

- Concluding evidence-based suggestion

In general, the neuroarchitecture tools still require further evaluation; regarding users' interaction, and their results linkage with the architectural principles. Also, the proposed research methodology of neuroarchitecture still requires more practical experiments to obtain a variety of viewpoints.

\subsection{Human Brain Overview}

Following is a summarized brief about the human brain, its composition and functions; made up of multiple researchers' point of view:

\subsubsection{The Human Brain Systems It consists of two systems:}

- System I (Fast thinking): Operates at an unconscious level

- System II (Slow thinking): Operates at a conscious level

The environmental stimulus affects the brain's system (I) by $99 \%$ relative to the brain's system (II), (Fig.1), which means that the built environment can impact the unconscious mind without even the awareness of the conscious mind. 


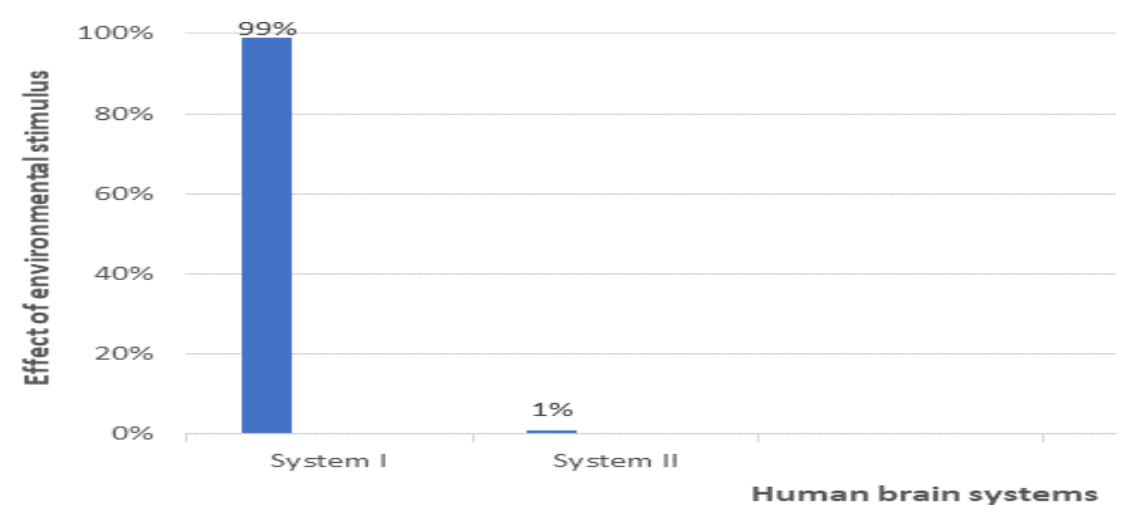

Figure 1: The difference between the brain systems in their relationship with the environmental stimulus

This functioning pattern of the brain systems supports the claim saying that the empirical tools cannot handle this complexity because conventional methods measure predominantly the conscious mind.

\subsubsection{The Human Memory}

It consists of two main functioning systems:

- Long term memory: It is updated by the conscious mind, influences the unconscious mind and the behavior. Also, the sensory pathways leading to it are increased by multisensory teaching.

- Short term memory: It is the active memory, characterized by being finite and related to attentional filters.

\subsubsection{The Attention Processes}

It is a finite resource that filters a lot of what we sense, it is also considered the gateway to long term memory. And, it could be activated by stimulating multiple senses at the same time.

All things considered, the information in this part was technical, more in depth in neurological knowledge; however, it explained the importance of the multi-sensorial stimulation in affecting the attention, and hence the long-term memory. 


\section{Neuroscientific Research Benefitting Architectural Design}

Due to the involvement and interfere of multiple fields, this research required in-depth study of the latest findings in neuroscientific research and experiments; reviewing technical information, as the raw material for Neuroarchitecture research and possible applications.

\subsection{Recent Findings Related to Architecture}

Briefly, the human brain contains chemicals on which it depends in the allowance of decoding to occur in order to facilitate the emotional responses. Among these chemicals are the neurotransmitters (Fig.2), whose balance is a must for the individual's mental and physical health.

The reason this neuroscientific detail is very important in Neuroarchitecture research is that experiences caused by the physical environment can cause the alteration of the production of eachneurotransmitter through natural stimulation.

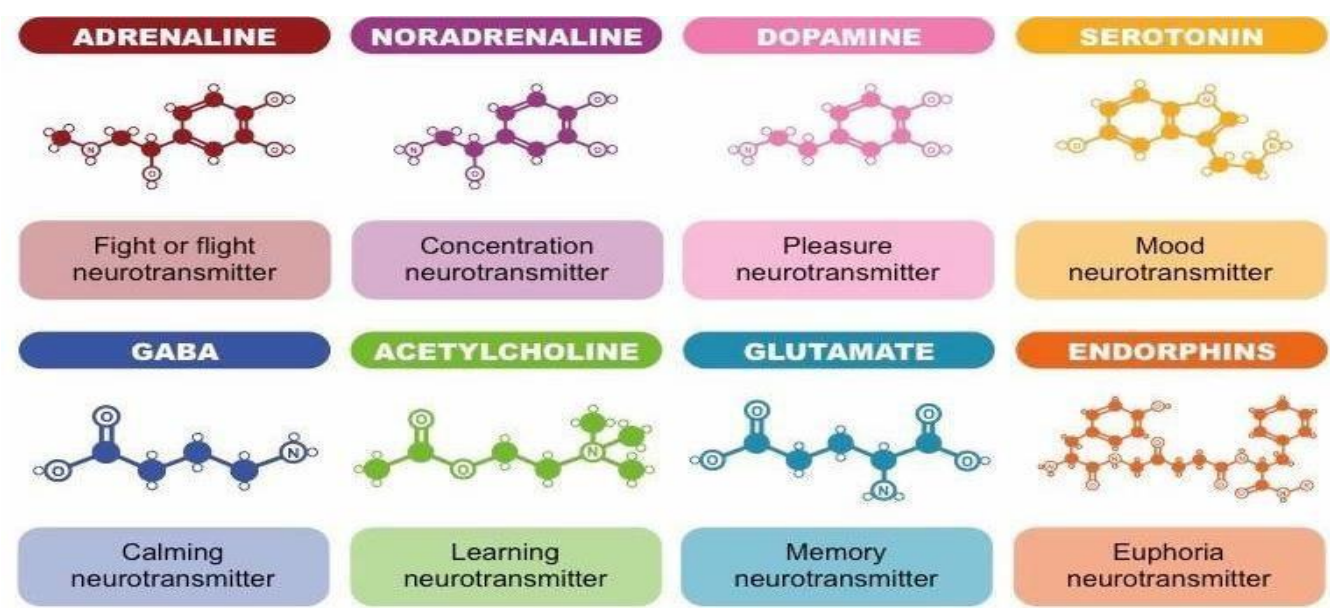

Figure 2: Chemical structure of neurotransmitters and their functions

Source:(https://www.theblendinstitute.com/blog/neurotransmitter-balancing-vspsychopharmcology)

Also, the brain's most related characteristics to the spatial experiences and the learning processes are the brain's neuroplasticity and the neurogenesis, defined simply according to Bergland (2017) as follows:

- Neuroplasticity: The ability of the brain to form new connections and pathways, and change the wiring of its circuits.

- Neurogenesis: The ability of the brain to grow new neurons. 
Also, a group of five researchers has studied the mechanisms underlying the effects of enriched environments on brain plasticity, depending on facts, proven theories, and experiments results, they documented their research work in their book "The Hippocampus - Plasticity and Functions".

They defined the neuroplasticity as the physiological changes in the brain that happen as a result of individual's interaction with the environment (social and physical), and characterized it as follows:

- Its best efficiency is during development and youth

- It is responsible of inducing lasting change to the brain throughout individual's life.

- It could be optimized by enriched environments, which improves behavioral performances

Another aspect related to that specific area of study, and covered by the same book, is the brain hippocampus plasticity.

Firstly, the hippocampus is a small curved formation in the brain that is involved in the formation of new memories, and associated with learning and emotions, and is mainly characterized by the high susceptibility to volume changes when experiencing stimulated environments, and the involvement in mood regulation, emotions, learning, and memory.

Furthermore, the research team has examined the results of the enrichment of the environment and its experience in modulating the hippocampus plasticity through:

1- The appearance of new neurons in the dentate gyrus and their survival.

2- The alteration of synaptic connections which results in:

- Neurotransmitter's release

- Change in number and shape of neurons connections 
3- The increment of neurotrophic factors in the hippocampus affecting neurogenesis, and synaptic plasticity; which promotes neuronal activity.

In spite of the scientific nature of this source and the indispensable need for the scientific terms' employment, it was very useful in constructing primary data to be invested and implemented as raw material for further research work.

However, despite all the research work focusing on the impact of the built environment on the individuals, the multiple variables involved in these impacts make it difficult to control and study how architecture can influence individuals.

In her article "Short and long-term effects of architecture on the brain: towards theoretical formalization" Paiva discussed the effect of the time and frequency of exposure to the built

Environment in shaping its impact on individuals, and classified its levels as follows (Fig.3):

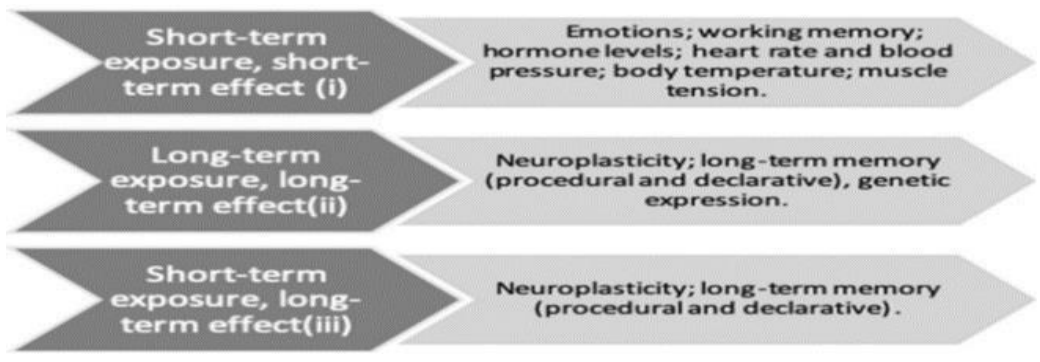

Figure 3: Proposed categories of biological adaptation of individuals to the environment

Source: Short- and long-term effects of architecture on the brain: Towards theoretical formalization (2019)

His words with the original facts he is relying on, but this could be due to the fluent mix between the scientific facts' implications, and The findings of such classification had connected multiple nodes; starting from the awareness of the degree of impact the architectural design can create on the individuals according to the building typeand the users type (short and long term users); right up to the potentials of controlling the exposure frequency to specific spaces in modifying the behavior and the performance; citing the previous experiments done on animals, studying 
the direct relation between Neuroplasticity \& spatial features of enriched environments, which led to a fact saying that long term exposure to specific built environment can help induce structural \& functional changes in the brain.

Generally, the author missed many times reinforcing its interpretations;but overall, the information are well researched and the assumptions are reasonable; leading to the formulation of basic environmental effects categories.

\subsection{Human Senses}

When talking about the spatial experience, how it occurs, and how individuals perceive the stimulus; we cannot neglect studying the gate linking between the external surrounding environment, and the human mind; which is the functioning system of the human senses. The human senses role in spatial perception could be dropped down into:

- The ability to recognize the geometrical structure of the surrounding environment.

- The awareness of self-location in the surrounding space.

- The determination of the location of nearby objects in terms of depth and directions.

- The ability to build a cognitive representation of the 3dimensional environment Thus, when the architectural experience becomes multi-sensory, all the senses are equally experiencing the quality of the space which will strengthen the existential experience.

The data in this part was a little bit elementary, but it gave an overview about the human senses' relationship with the architectural features. Also, it shed light on the proven clue of the multi-sensorial perception of spaces. 


\subsection{Neuroscientific Findings Applications}

A considerable number of researches focused on the interpretation of neuroscientific research findings correlations with architecture, which is considered raw materials for further potential applications.

- Priming The Brain Through Architecture

It means exploiting the potentials of influencing the individual's behavior without conscious realization; depending on the functioning system of the senses.

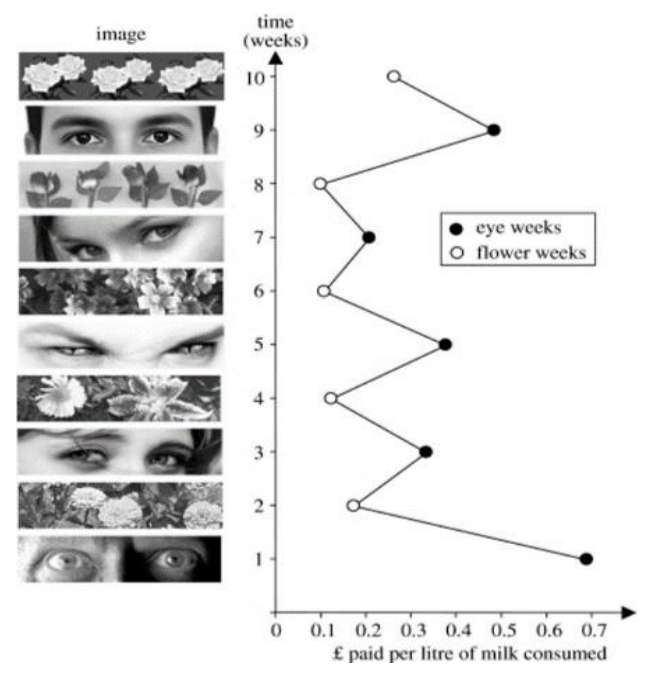

Figure 4: The rate of honest behavior of payment as function of weekly image type Neuroscience for Architecture: How Building Design Can Influence Behaviors and Performance

For further explanation, Paiva demonstrated in her paper "Neuroscience for Architecture: How Building Design Can Influence Behaviors and Performance" experiments done as applications on this area of study; such as The honesty box experiment: a study done in British University that aimed to lead the staff of an office into an honest behavior through various visual shapes over a period of ten weeks. The results (Fig.4) showed that when the visual sense captures visuals expressing observation and surveillance feeling, like human eyes, the behavior was more significantly honest. 


\section{- Enriched Environment Experiments on Rodents}

Multiple studies took the scientific aspects of the brains and the hippocampus plasticity into a new practical level; where rodents were used to explore the effect of the surrounding environment on the brain. The previously mentioned book "The hippocampus - plasticity and functions" analyzed one interesting experiment done with that approach.

Firstly, the rodents were exposed to enriched environments (Fig.5) mainly characterized by sensory stimulation, social interaction inducement, and physical activity. The effects of these environments were found very promising, with unprecedent improvement in multiple neurological features.

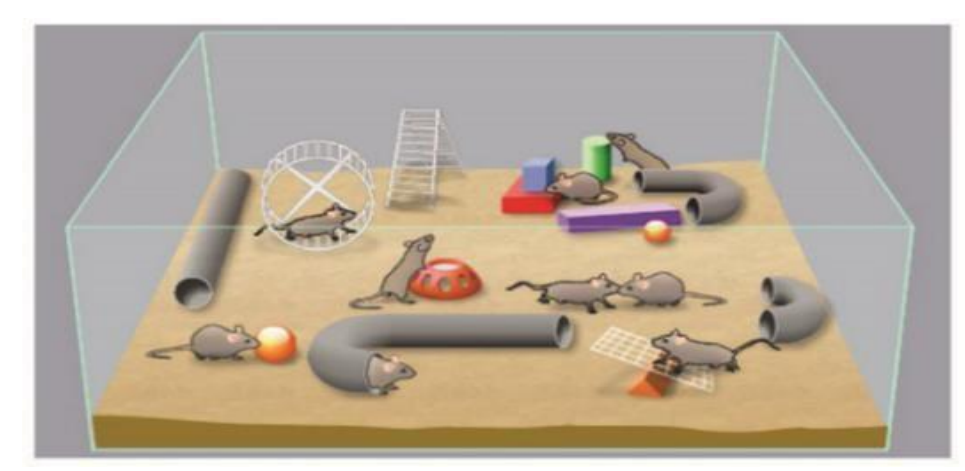

Figure 5: Illustration of the rodents enriched environments Source: How Does an Enriched Environment Impact Hippocampus Brain Plasticity (2018)

What was really beneficial in this study was how it discussed the scientific explanation of theresults, and then projected it on the human enriched environment, inspired from rodents.

Despite the deficiency in boosting this research part with proven clear facts, it translated the summary of neurological information, explained previously in the same paper, into the architectural language and elements; and it totally relied on logical reasoning and reasonable assumptions. 


\subsection{Key Architectural Interpretations}

Simultaneously, few researches have begun to interpret the actual findings directly in the architectural field. Topped by the architectural projected conclusions of the rodent's experiments, published in the paper "Short- and long-term effects of architecture on the brain: towards theoretical formalization".

Another interesting aspect was studied, which is the physical space ability to evoke emotions.

The physical space elements, able to evoke the universal emotions, innate to all human beings are determined by Paiva as follows:

- Ceiling height

- Proportions

- Textures

- Lighting

- Shapes

- Colors

- Temperatures

- Smells \& Sounds

The importance of such interpretation lies in the role of emotions in influencing the way people perceive the world. So, people may perceive spaces differently due to their mental and emotional state that could be primarily affected by the surrounding built environment.

Unfortunately, the linkage between the human emotions and the architectural elements requires more research and observation to obtain respective relationship between each architectural element and its affected emotions. 


\section{Children Brain Development and The Learning Processes}

All things considered, it is clear that the built environment has an obvious impact on the individual's brain; citing the neurotransmitters, neuroplasticity ... etc., and hence, on the behavior, performance, and wellbeing of individuals. However, these potential powers of architecture are not limited to this, they are already stretched out to affect the children brain development, taking these potentials to a new level where architecture affects individuals with long term effects throughout their life span.

\subsection{Relationship with Surrounding Built Environments}

According to Bronfenbrenner (1977, 1979, 2004), the factors affecting children development are:

- The developing person (genes)

- The environment (Immediate $\&$ remote)

- The continuities \& changes occurring in the environment overtime.

This is consistent with the claim firstly formulated by Santiago Ramon, saying that the environment can cause long term changes in the brain. Identically, Paiva explained that several critical periods of the development of specific abilities occurs during childhood.

For all those reasons, we need to understand specifically how and to what extent, specific features of children's environments affect specific elements of healthy children development; this exact point is where neuroscientific research plays a major role; where the recent neurological tools are used to measure children development quality. Giving example, the EDI (Early development index), used to measure the readiness to learn; which means the state of the child's neuro-system being ready to develop neuropathways and various skills. 
Also, as discussed before, it is affirmed that the brain neuroplasticity and neurogenesis are both affected by the environmental stimulus. As an example, Paiva analyzed the architectural design role in stimulating circulation through spaces to encourage walking and movement by the design of attractive pathways, enjoyable scenery and hills; all of this for the goal of improving the physical activity, which stimulates the production of brain-derived neurotrophic factor, a substance that helps in:

- Neuronal growth

- Maturation

- Maintenance

\subsection{Children's Brain Development Processes}

To be able to work on the built environment impacts on children, it is essential to briefly understand all the aspects of healthy children development.

According to Dunn (2012), the domains of healthy child development are established, based on the research work of Doherty (1977), as follows:

1. Social knowledge and competence.

2. Emotional development and maturity

3. Language development

4. Cognitive development

5. Healthy physical development

6. Communication skills \& generalknowledge

Certainly, this data is focusing on children development aspects from a pure neurological and psychological perspective. That's why Dunn (2012) interpreted the studies done in Vancouver about the effects of the surrounding environments on children's readiness to learn (Oliver et al. 2007), (Fig.6) 


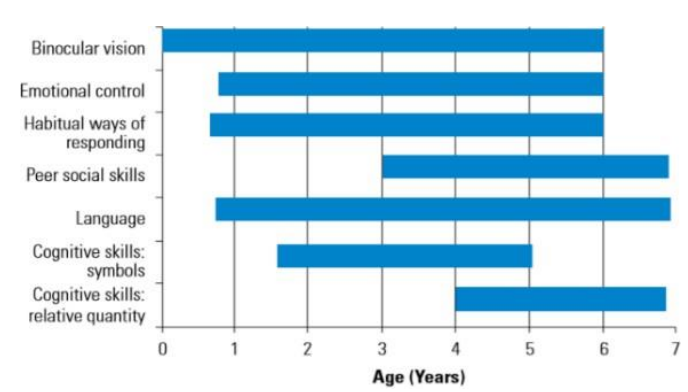

Figure 6: The sensitive periods for various domains of healthy child development

Source: Levels of Influence in the Built Environment on the Promotion of Healthy Child Development (2012)

Conclusively, the logical organization of the information made it easy to interpret conclusions asfollows:

- The effects of the environmental factors are more efficient and obvious starting from the child's 3rd year, due to the expansion of his geographical range.

- The architectural design of the built learning environment mostly contributes to the improvement of specific elements of healthy child development: the $3^{\text {rd }}, 4^{\text {th }}, 5^{\text {th }}$, and $6^{\text {th }}$ elements particularly, not all of them.

In general, this part added new information related to the specific area of study about children development aspects from the neurological \& psychological perspectives but it didn't cover completely the linkage with the built environment design features $\&$ characteristics.

\section{Neuroarchitecture in Learning Environments}

Current studies showed the important role the design of the spaces, occupied by children, plays in affecting their healthy growth and development. From a pedagogical perspective, the physical environment is considered as a "Third teacher"; which is a spatial framework for learning processes that facilitate the development of children (Mau et al., 2010). 


\subsection{Neuroscientific Findings Related to Learning Environments}

Neuroarchitecture application in the scope of educational spaces design was firstly conducted by ANFA, the Academy of Neuroscience for Architecture, in 2005. It focused on the physical environment effects on the brain learning engines; focus, attention, and cognition. ANFA studied specific features, strongly affected by the design of educational facilities as follows:

- Wakefulness: the ability to stay alert throughout the day

- Focus and attention

- Neurogenesis: the growth of new neurons from neural stem cells

- Stress reduction: Stress levels are strongly related to the subject of rationality

Therefore, the neurological findings projected on educational facilities were analyzed, focusing on the learning-oriented brain areas, as follows:

- The occipital \& parietal brain regions: related to focus, attention, \& cognition,(Fig.7).

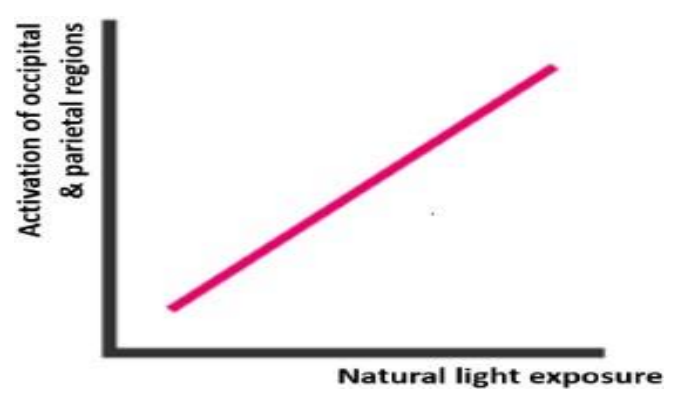

Figure 7: Natural light exposure vs. occipital \& parietalbrain regions activation

Source: Authors 
- The prefrontal lobe: related to rationalreasoning, (Fig.8).

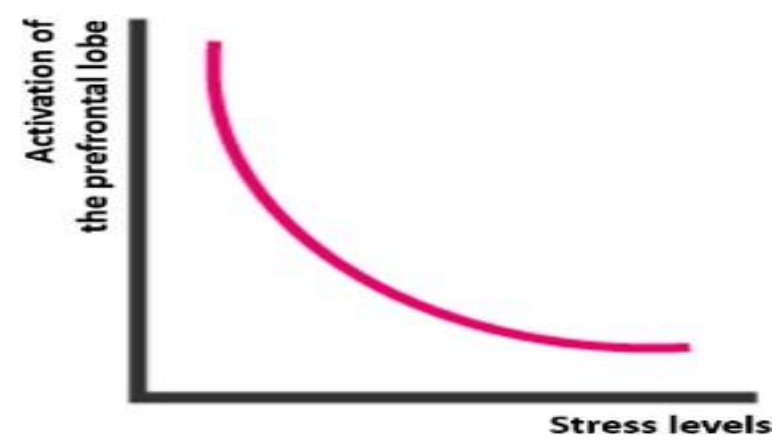

Figure 8: Stress levels vs. prefrontal lobe activation Source: Authors

- The sleep hormones found in humansaliva: related to concentration and attention, (Fig.8).

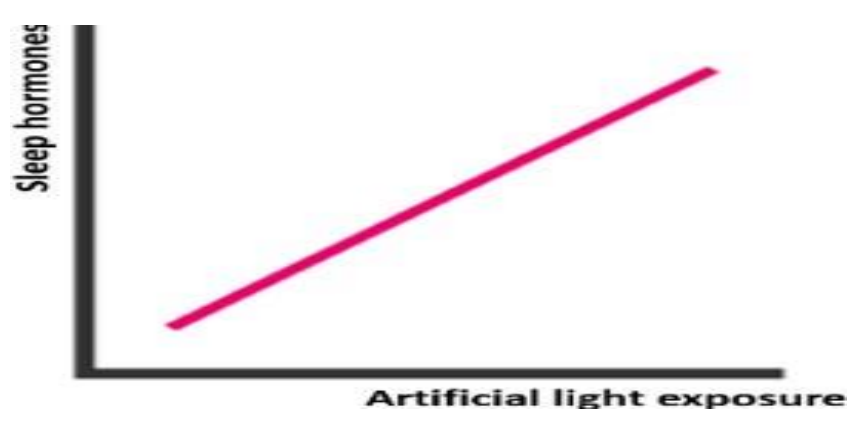

Figure 8: Artificial light exposure vs. sleep hormones Source: Authors

\subsection{Applied Experiments on Educational Spaces Assessment}

The continuous research for innovative strategies of the upgrading process of schools buildings design has shed light on two important aspects that should be incorporated; the pedagogical concepts, previously discussed, and the needs \& demands of the school users; which take us back to the point of student's perception of the built environment, their expectations and needs. 
In order to realize the valuable contribution of children in the implementation of their age-specific needs, the planners need new tools to collect and analyze their needs and to evaluate the school environment; that's why it was inevitable to investigate the experiments that succeeded in creating a paradigm shift in the inclusion of children in the design process and in the exploration of their needs.

Following is a brief about a pilot study done in an elementary school in Darmstadt, Germany, in 2016; creating a toolkit to be used in childled assessments of spaces where children are the active users. Firstly, a set of spatial categories was formulated, (Table 1), to be used by children in order to investigate and analyze their specific needs, simplified in an explicit manner as follows:

Table 1: Spatial categories with an explanation text, shown on screens Source: MoMe@school - A pilot study on an analytical and participatory tool for active learning spaces design (2017)

\begin{tabular}{|l|l|}
\hline \multicolumn{1}{|c|}{ Category } & \multicolumn{1}{|c|}{ Explanation text } \\
\hline Relaxing & I feel relaxed here. I can recover and rest without worries. \\
\hline $\begin{array}{l}\text { Suitable for physical } \\
\text { activity }\end{array}$ & I can move around and be active here. \\
\hline My favorite place & I like it very much here, I can do a lot here and I always feel comfortable doing it. \\
\hline Good place to study/learn & I can always study well and comfortably here. \\
\hline A place I dislike & I don't feel comfortable or at ease here. \\
\hline
\end{tabular}

Just in the same way, children were asked to rate the spaces according to the six core aspects of environmental \& behavioral experience, (Knoll et al.,2015), presented as opposite objectives in formof stickers instead of the semantic differential scale, (Fig.10). 


\begin{tabular}{|c|c|c|}
\hline Colleggory & Minimum & Maximum \\
\hline Space & namow & wides \\
\hline Vegetation & poor megetation & much vegpetation \\
\hline Llohting & dark. & Eright \\
\hline Noise & quiet & lanud \\
\hline Sesating & $\begin{array}{l}\text { Lever seating } \\
\text { wrailable: }\end{array}$ & $\begin{array}{l}\text { pleasinty of } \\
\text { seasing anvaliable }\end{array}$ \\
\hline Relaxation & streassfut & ratasing \\
\hline
\end{tabular}

Figure 10: The six polar adjectives describing environmental \& behavioral experiences and their representation as stickers Source: MoMe@school - A pilot study on an analytical and participatory tool for active learning spaces design (2017)

It was introduced to children in form of a mobile application "I spy with my little eye", (Fig.11) ensuring enjoyable experience by their free navigation and the photographs they took for the spaces.

Subsequently, the use of digital technology demonstrated some benefits in helping designers analyze children perception of their learning environment, since children rated the process as an enjoyable and positive experience.

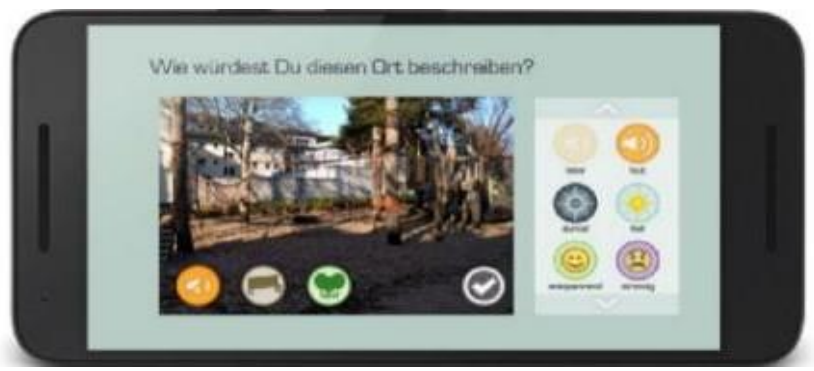

Figure 11: Screenshot of the mobile application. "How would you describe this space?"

Source: MoMe@school - A pilot study on an analytical and participatory tool for active learning spaces design (2017) 
Lastly, the third step of the toolkit was a hands-on workshop, where children were encouraged to share their ideas and visions using mood boards, drawings, and collages, (Fig.12).

The benefits of this step were mainly about how it allowed researchers to learn what students wish to change in their spaces and their proposed modifications.

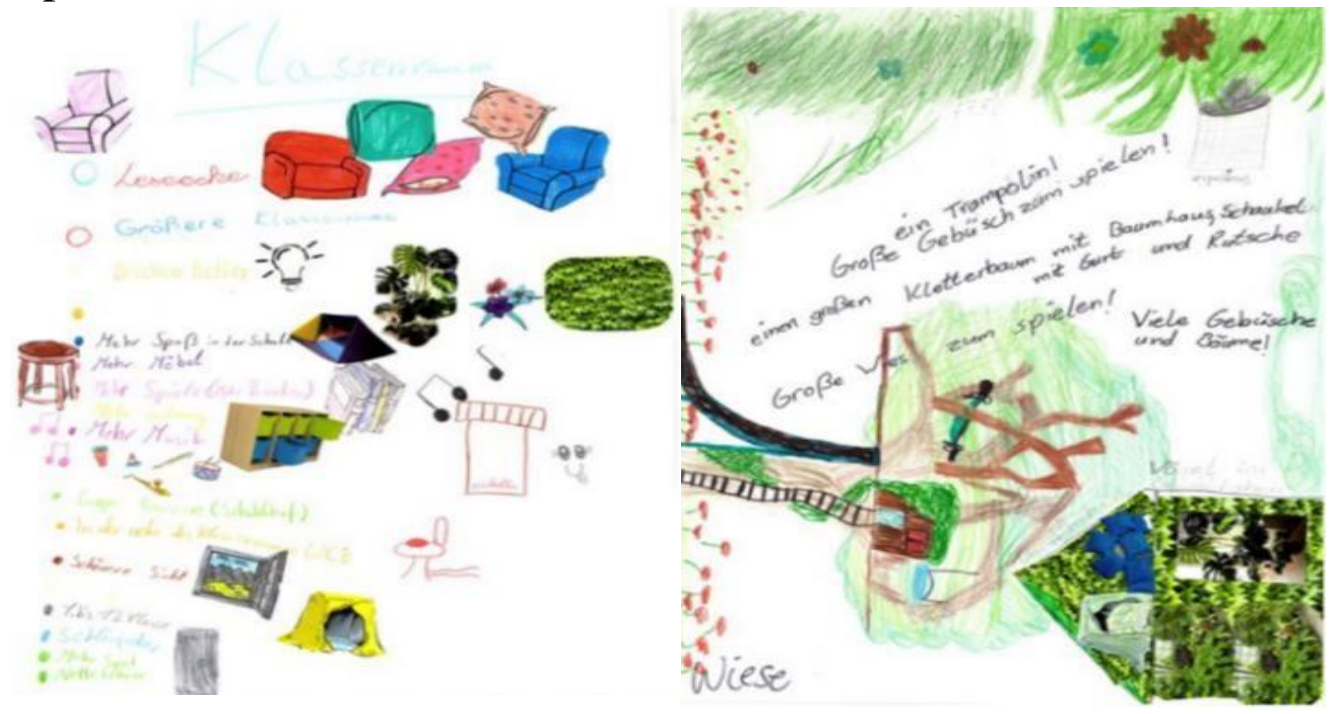

Figure 12: Children collage describing their vision

Source: MoMe@school - A pilot study on an analytical and participatory tool for active learning spaces design (2017)

However, despite being a very integral example of the implementation of creative and new ideas of applications, it is taken on this experiment that it didn't clearly mention the neuroscientific base of itsinterpretations and conclusions; but still it was built on logical reasoning and impartial viewpoints.

\subsection{Classroom Design Overview from a Neurological Perspective}

Despite the lack of the direct conclusions and the realistic results in the majority of the research workin the field of neuroarchitecture, and especially in its application in the educational facilities design, aset of theoretical guidelines have been created; concerning the educational spaces, and benefitting from the retail design guidelines, widely discussed, on a neurological basis.

The optimal functions of the architectural spaces were examined, (Table 2), as well as their equivalent spatial characteristics (Holmes, 2016). 
INTERNATIONAL JOURNAL OF

ARCHITECTURAL ENGINEERING AND URBAN

RESEARCH

VOLUME 4, ISSUE 1, 2021, 67-94.

Table 2: The proposed spatial characteristics equivalent to the optimal functions Source: Authors

\begin{tabular}{|c|c|c|}
\hline Space type & Optimal functions & Equivalent spatial characteristics \\
\hline \multirow[t]{5}{*}{$\begin{array}{l}\text { 1. Group } \\
\text { gathering space }\end{array}$} & $\begin{array}{l}\text { Improvement in audibility and visibility for attention } \\
\text { enhancement }\end{array}$ & $\begin{array}{l}\text { Creating clear equal lines of sight for all } \\
\text { students }\end{array}$ \\
\hline & Removal of possible distractors & $\begin{array}{l}\text { Solving physical discomfort and storage } \\
\text { spaces under seats }\end{array}$ \\
\hline & $\begin{array}{l}\text { Student's engagement in the physical design of the } \\
\text { space }\end{array}$ & Adding extra seating cushions \\
\hline & $\begin{array}{l}\text { Enhancement of shared learning and active } \\
\text { discussions }\end{array}$ & Removing desks barriers \\
\hline & $\begin{array}{l}\text { Creation of a bond between the students \& the } \\
\text { environment they learn in; to help anchor concepts } \\
\text { and facilitate recall }\end{array}$ & $\begin{array}{l}\text { Enriching the look and feel of the space } \\
\text { (since it is linked to the learning memory) }\end{array}$ \\
\hline \multirow[t]{3}{*}{$\begin{array}{l}\text { 2. Collaboration } \\
\text { space }\end{array}$} & $\begin{array}{l}\text { Investment of the role of play in learning (Mirror } \\
\text { neurons) }\end{array}$ & $\begin{array}{l}\text { Creating highly flexible space with } \\
\text { reconfigured seating }\end{array}$ \\
\hline & $\begin{array}{l}\text { Visual communication (Sketching - Scribing); since it } \\
\text { strengthens the neuronal pathways in the brain, } \\
\text { providing additional routes to enable recall from long- } \\
\text { term memory }\end{array}$ & $\begin{array}{l}\text { Designing tables with surfaces that could } \\
\text { be written on }\end{array}$ \\
\hline & $\begin{array}{l}\text { Student's engagement in the physical design of the } \\
\text { space }\end{array}$ & $\begin{array}{l}\text { Letting students arrange seating's \& tables; } \\
\text { insuring personalized spaces }\end{array}$ \\
\hline $\begin{array}{l}\text { 3. Contemplation } \\
\text { space }\end{array}$ & $\begin{array}{l}\text { Improvement of the ability to suppress external } \\
\text { distractions (mindfulness) }\end{array}$ & $\begin{array}{l}\text { Designing spaces with soft lines, curved } \\
\text { edges, and softer seating; to facilitate } \\
\text { relaxation and deaden sound }\end{array}$ \\
\hline 4. Digital space & Focus in research & Creating clean lines and simple design \\
\hline \multirow[t]{2}{*}{ 5. Maker space } & $\begin{array}{l}\text { Priming students to increase their exploratory \& } \\
\text { potentially creative behavior }\end{array}$ & $\begin{array}{l}\text { Implementing natural materials, to let its } \\
\text { imperfections prime the students to focus } \\
\text { less on perfection \& precision and to be } \\
\text { more innovative }\end{array}$ \\
\hline & $\begin{array}{l}\text { Support easy collaboration between adjacent } \\
\text { workstations }\end{array}$ & $\begin{array}{l}\text { Using materials like brick, wood, metal } \\
\text { work, and a bar like design }\end{array}$ \\
\hline \multirow[t]{2}{*}{ 6. Storage space } & $\begin{array}{l}\text { Deliberate physical activity; to increase the flow of } \\
\text { fresh oxygen to the brain }\end{array}$ & $\begin{array}{l}\text { creating spaces for movement to energize } \\
\text { students }\end{array}$ \\
\hline & Freed up visual noise to concentration and focus & $\begin{array}{l}\text { Creating flexible space that could be } \\
\text { possibly hidden }\end{array}$ \\
\hline
\end{tabular}

Also, some general principles were extracted, according to their benefits on the level of the degree and type of effect they exert on the brain:

- Well-designed classroom may contribute to a release of pleasure by enhancing neurochemicals release in the brain (Opioids \& Dopamine); which will result in automaticseeking out to this specific space

- Strong identity of each zone can anchor the learning processes in long-term memory 
- Use of colors, shapes, and materials in creating positive emotional responses to spaces can make the classroom a tool incorporated in lesson planning, and used to improve the educational experience for students and teachers

The data in this source suffered from not being totally strengthened by scientific explanations; as some parts could be considered as opinions evolved from interpretation of facts, and that the author didn't mention clearly the common design aspects between retail spaces and classrooms to be persuasive about that projection on learning spaces design; however, this research could be considered a valuable contribution to the field of neuroarchitecture, because it translated conclusions from neuroscience to real design elements.

\section{Conclusion}

This paper reviewed multiple literature resources about the multiple correlated topics, ranging between published papers, experimental researches, and scientific articles. 19 published works were overviewed and analyzed; but the majority of data relied only on 8 sources, extensively analyzed in detail.

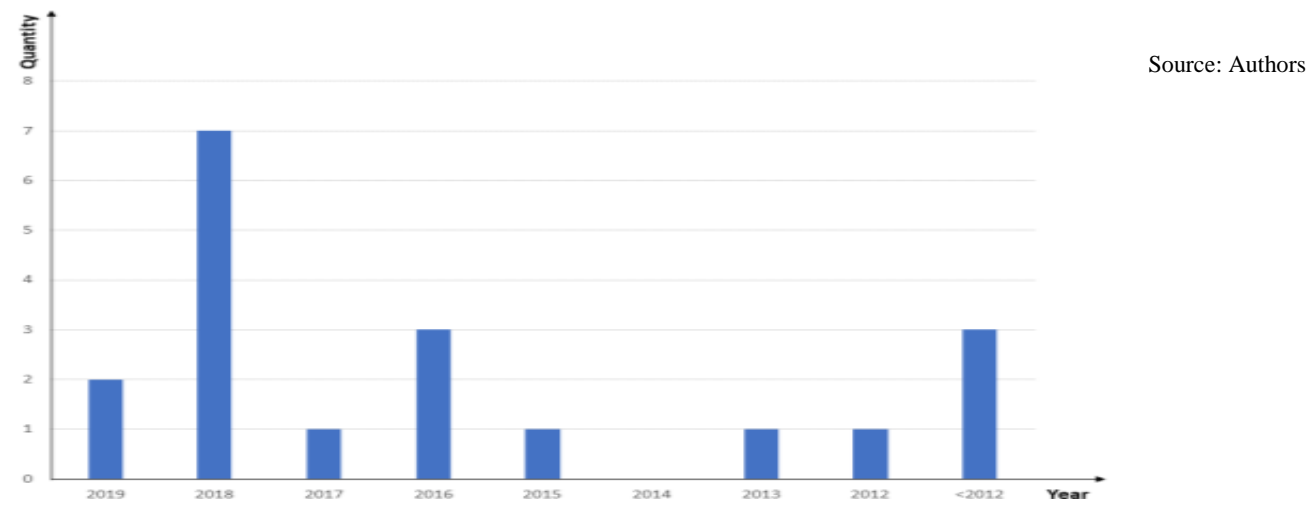

Figure 13: Literature publications per year Source: Authors 


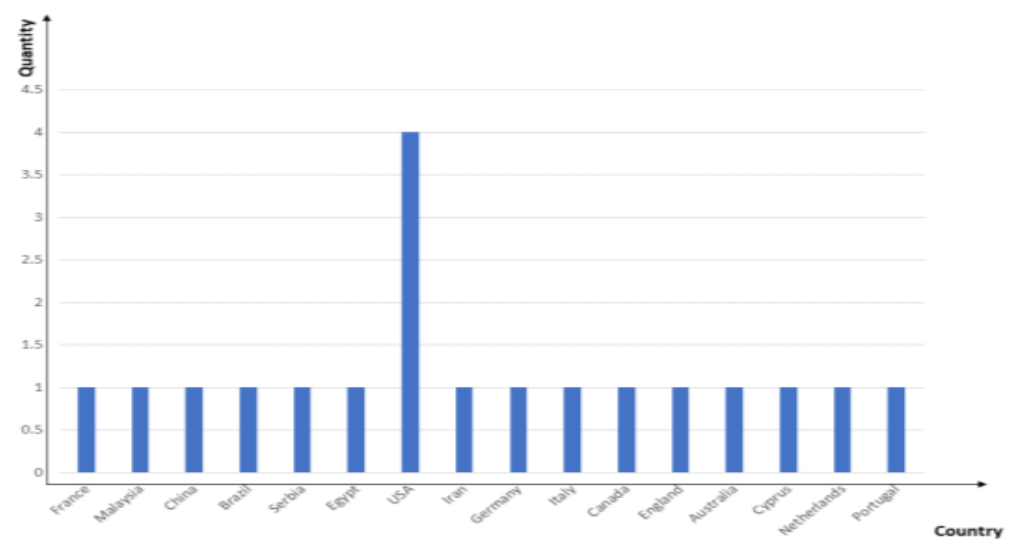

Figure 14: Number of literature publications per country

Source: Authors

As shown in Fig.13, the oldest reviewed sources go back to 2008 maximum. And 2018 is consideredthe highest in the series with 7 publications. Also, it is clearly noticeable that researches from USA are predominant, with percentage approximately $21 \%$ of total publications, (Fig.14).

Despite all that has been reached in the emerging field of neuroarchitecture, it still has a long way to go in scientific research and practical experiments until the fruition of its evidence-based design guidelines.

The findings related by any means to Neuroarchitecture in the neuroscientific field are enormous; but if we can conclude the main promising information to build on (Fig. 15), it will be the following:

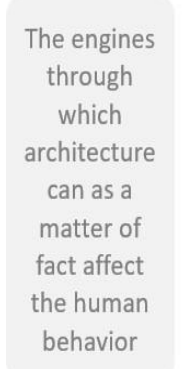

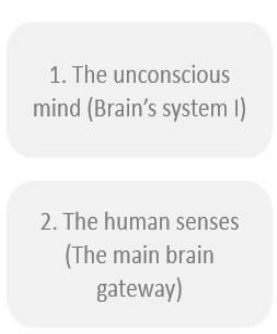

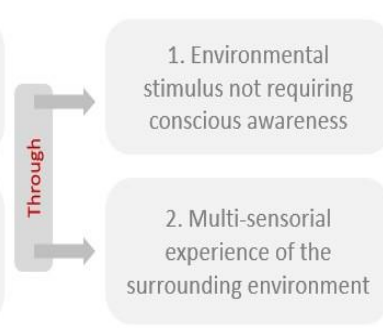

Figure 15: The key extracted information
The indispensable

need for

experiments \&

measurement tools

that are directed to

measure the real

effects of the

environment, not

only the consciously

perceived effects

Source: Authors 
Another significant evidence obviously concluded, is the uniqueness of each architectural project; Which sheds light on the issue that the field of neuroarchitecture, even after the awaited research, won't create a reliable generalized framework. However, the targeted vision is tailored design guidelines to categorized building types, flexible enough to include possible cultural and personal adaptations.

Accordingly, from a totally different research scope, focusing on the human emotions, the interchangeable relationship between the built environment and the individuals was stronglyhighlighted (Fig.16).

From where we can conclude a new possible potential of architecture to affect learning, memory, and attention, through the creation of intense emotional responses within intended architectural features.
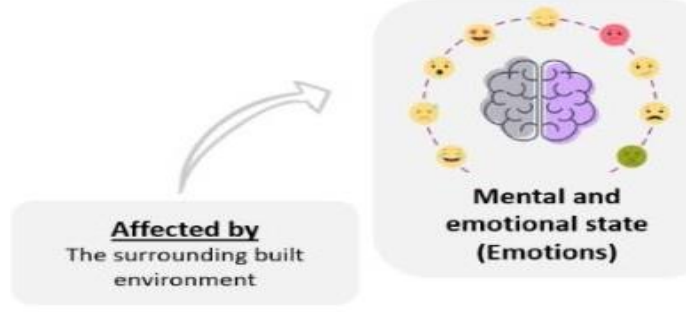

Figure 16: The relationship between the emotions, the built environment \& its perception

Correspondingly, another critical subject has been addressed, which is how architecture, with the environments it creates, is considered one of the main few factors affecting children's healthy development, a lifetime impact. Luckily, this specific area of study has gained relatively some solid credit; where the initial characteristics of the desired architectural environment were generated, withfew successful examples of how scientifically do these features affect children's brain development; however, it still requires a lot of research and practical experiments. 
To summarize, this paper succeeded relatively in its main purpose. It insured the exploration and analysis of the basic information about the interdisciplinary fields; and tried to simplify the scientific expressions from neuroscience, psychology, and pedagogy, unfamiliar to architecture.

It also tackled a lot of researches with similar goals. And then finally, it reconciled consistent information from the various research directions; to reach valuable conclusions. However, it was definitely negatively affected by the lack of researches focusing on the same exact topic, making it difficult to deduce final conclusions in many issues; since there are already few viewpoints.

\section{List of references}

- Ahmad, C., Amirul, N., 2018. "The effect of the physical environment on students, health, enjoyment, and learning". Malaysia: Journal Pendidikan Sains Dan Matematik.

- Arellano, M., 2015. "Hawaian Healing Center: A weaving OF Neuro-Architecture and cultural practices". The University of Hawai' $i$ at Manoa.

- Australian Early Development Census, 2019. "Brain development in children". Australia: Commonwealth of Australia.

- Barrett, P., etel, 2015. "The impact of classroom design on pupils' learning: final results of a holistic, multi-level analysis". Elsevier Ltd.

- Buday, R., Baranowski, T., 2018. "Behavior-aided Design: A Translational Approach to Persuasive Architecture". Shared behavioral outcomes, ANFA, Archimage press.

- Charehjoo, F., Etesam, I. \& Rasoulpour, H., 2018. "The Role of Environmental Psychology in Architecture and Urban Design". Sanandaj, Iran: Journal of Architecture and Construction Volume 1, Issue 2. 
- Clemenson, G., Deng. W., 2015. "Environmental enrichment and neurogenesis: From mice to humans". Elsevier Ltd.

- Coburn, A., Vartanian, O. \& Chaterjee, A., 2017. "Buildings, Beauty, and the Brain: A Neuroscience of Architectural Experience". Pensylvania: University of Pennsylvania ScholarlyCommons.

- Dunn, J.,2012. "Levels of Influence in the Built Environment on the Promotion of Healthy Child Development". Canada: Healthcare Quarterly, Vol.15, Special issue.

- Eberhard, J., 2009. "Applying neuroscience to architecture". Cell press.

- Elseragy, A., Elnokaly, A., Gabr, M., 2011. "Building Sustainable Learning Environments that are 'Fit for the Future' with Reference to Egypt". World sustainable building conference, Helsinki, Finland.

- Foster, V., Hollander, J., 2016. "Brain responses to architecture and planning: a preliminary neuro-assessment of the pedestrian experience in Boston, Massachusetts". Architectural Science Review, Vol.59,No.6,474-481.

- Hadjiphilippou, P., 2013. "The contribution of the five human senses towards the perception of space". Cyprus: SDU, Sustainable Design Unit.

- Hayes, D., Berman, M. \& Krpan, K., 2015. "Environmental Neuroscience and Environmental Psychology". England: Oxford bibliographies.

- Holmes, T., 2016. "The Neuroscience of Classrooms". England: Spaceoasis Ltd.

- Ibrahim, M., 2019. "The Integration of Interior Design and Neuroscience: Towards a Methodology to Apply Neuroscience in Interior Spaces". Egypt: Journal of art \& architecture research studies. 
- Ken, A., "The Psychology of Learning Environments". Minnesota, USA: Winona State University. https://www.educause.edu/research-andpublications/books/learning- spaces/chapter-6-psychologylearning-environments

- Maleki, M., Bayzidi, K., 2018. "Application of Neuroscience on Architecture: The emergence of new trend of Neuroarchitecture". Kurdistan: Kurdistan Journal of Applied Research.

- Matthews, E., Lippman, P., 2016. "The Physical Environment of Early Childhood Centers: A Case Study in the use of BreakOut Spaces". International Journal for Cross-Disciplinary Subjects in Education (IJCDSE), Vol.7, Issue 2.

- Miranda, M., Ustinova, M., Knoll, M., 2017. "MoMe@school - A pilot study on an analytical and participatory tool for active learning spaces design". Germany: Journal of Urban Design and Mental Health.

- Moneim, W., 2005. "Architecture and Human Behavior, Does Design Affect Our Senses?”.Egypt: Journal of The Egyptian Society of Engineers.

- Paiva, A., 2018. "Neuroscience for Architecture: How Building Design Can Influence Behaviorsand Performance". São Paulo, Brazil: Journal of Civil Engineering and Architecture.

- Paiva, A., Jedon, R., 2019. "Short- and long-term effects of architecture on the brain: Towardstheoretical formalization". Frontiers of Architectural Research, Vol. 8, Issue 4.

- Pallasmaa, J., etal, 2016. "Architecture and Neuroscience". the Tapio Wirkkala-Rut Bryk Foundation.

- Ramli, N., Ahmad, S., Masri, M., 2013. "Improving the classroom physical environment:Classroom users's perception". Malaysia: Elsevier Ltd. 
- Reeves, H., 2012. "Human perception and the built environment: A Proposed Autism LifeLearning Centre for Durban". University of Kwazulu-Natal, Durban, South Africa.

- Ricci, N., 2018. "The Psychological Impact of Architectural Design". California, USA: ClaremontMcKenna College. http://scholarship.claremont.edu/cmc theses/1767

- Robinson, S., Pallasmaa,J., 2017. "Mind in Architecture: Neuroscience, Embodiment, and theFuture of Design". The MIT Press.

- Ruzzon, D., 2018. "A qualitative leap in school buildings the alliance between neuroscience andarchitecture" https://medium.com/@lombardini22/a-qualitative-leap-inschool-buildings-the- alliance-between-neuroscience-andarchitecture-e596273538e9

- Samaržija, H., 2018. "Epistemological Implications of Neuroarchitecture". Serbia:SAJ, SerbianArchitectural Journal.

- Sona, C.N., Shailaja, N., 2014. "Understanding Multisensory Architecture: A look at why it isimportant to include a person's complete body in the spatial experience, making it unique". India: Architecture: time, space \& people. https://coa.gov.in/show_img.php?fid=148

- Tabatabaian, M., Rezakolai, S., Fayaz, R., 2017. “Analysis the effect of the built environmenton children's creativity (Review the effect of the environmental characteristics on children's creativity in Tehran children centers)". Iran: The Scientific Journal of NAZAR research center(Nrc) for Art, Architecture \& Urbanism

- Techau, D., Owen, C., Paton, D. \& Fay, R., 2016. "Buildings, Brains and Behavior: Towards anaffective neuroscience of architecture". World health design

- Wall, K., Dockrell, J., Peacey, N., 2008. "Primary Schools: The built environment". USA:University of Cambridge. 
- Webber, L., 2018. “Significant Results. Space Makes a Difference Increasing StudentAcademic Engagement Levels". ESI: European Scientific Journal.

- Zarif, H., etal, 2018. "How Does an Enriched Environment Impact Hippocampus Brain Plasticity?". France: IntechOpen+ 